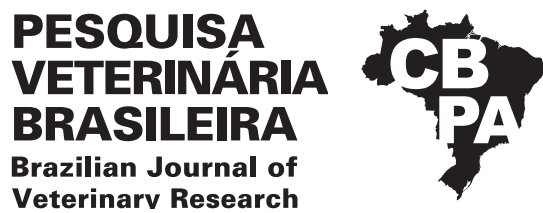

\title{
Eimeria spp. infection in lambs from southern Brazil ${ }^{1}$
}

\author{
Natália S. Martins ${ }^{2}$ (D), Sara P. da Motta², Carolina C. Santos², Andrios S. Moreira², \\ Nara A.R. Farias ${ }^{3}$ and Jeronimo L. Ruas ${ }^{4 *(1)}$
}

\begin{abstract}
Martins N.S., Motta S.P., Santos C.C., Moreira A.S., Farias N.A.R. \& Ruas J.L. 2020. Eimeria spp. infection in lambs from southern Brazil. Pesquisa Veterinária Brasileira 40(11):871-874. Departamento de Microbiologia e Parasitologia, Instituto de Biologia, Universidade Federal de Pelotas, Campus Universitário, Travessa André Dreyfus s/n, Capão do Leão, RS 96010-900, Brazil. E-mail: jeronimo.ruas@gmail.com

Eimeria infections are common in the sheep industry worldwide. Lambs are more susceptible to coccidiosis, especially in stressful conditions, being infected by different species of the parasite. Eimeria crandallis and Eimeria ovinoidalis are considered the most pathogenic, causing reduced growth, dehydration, anorexia, and death. In this study, the frequency of Eimeria species was evaluated in lambs from the southern region of the Rio Grande do Sul state, Brazil. Fecal samples from 248 lambs, from 19 farms, were tested for the presence of oocysts. The positive samples were re-examined and the sporulated oocysts analyzed morphometrically to identify the presence of Eimeria species. In $100 \%$ of the evaluated farms, there were animals positive for the protozoan. The frequency of Eimeria species was: E. ovinoidalis (94.74\%), E. crandallis (89.47\%), E. granulosa (78.95\%), E. parva (68.42\%), E. ahsata (63.13\%), E. punctata (42.11\%), E. bakuensis (36.84\%), E. faurei (10.53\%), and E. pallida (5.26\%). Mixed infection was found in $94.74 \%$ of the samples. This research describes, for the first time, the occurrence of E. crandallis and E. ovinoidalis infecting lambs in the study area. The wide distribution of this protozoan and the high frequency of pathogenic species show the importance and potential damage of sheep coccidiosis in herds from Rio Grande do Sul.

INDEX TERMS: Infection, lambs, Brazil, sheep industry, coccidiosis, Eimeria crandallis, Eimeria ovinoidalis.
\end{abstract}

RESUMO.- [Infecção por Eimeria spp. em cordeiros do sul do Brasil.] As infecções por Eimeria são comuns na ovinocultura mundial. Cordeiros são mais suscetíveis a coccidiose, especialmente em condições estressantes, sendo infectados por diferentes espécies do parasito. Eimeria crandallis e Eimeria ovinoidalis são consideradas as mais patogênicas, causando redução do crescimento, desidratação, anorexia e morte. Neste estudo, a prevalência de Eimeria spp. foi avaliada em cordeiros da região sul do Estado do Rio Grande do Sul, Brasil. Amostras fecais de 248 cordeiros, provenientes de 19 fazendas, foram testadas quanto à presença

\footnotetext{
${ }^{1}$ Received on August 17, 2020.

Accepted for publication on August 31, 2020.

${ }^{2}$ Graduate Program in Microbiology and Parasitology, Departamento de Microbiologia e Parasitologia, Universidade Federal de Pelotas (UFPel), Av. Eliseu Maciel s/n, Capão do Leão, RS 96160-000, Brazil.

${ }^{3}$ Departamento de Microbiologia e Parasitologia, Instituto de Biologia, Universidade Federal de Pelotas (UFPel), Campus Universitário, Travessa André Dreyfus s/n, Capão do Leão, RS 96010-900, Brazil.

${ }^{4}$ Laboratório Regional de Diagnóstico, Universidade Federal de Pelotas (UFPel), Av. Eliseu Maciel s/n, Capão do Leão, RS 96160-000, Brazil. *Corresponding author: jeronimo.ruas@gmail.com
}

de oocistos. As amostras positivas foram reexaminadas e os oocistos esporulados analisados morfometricamente para identificação das espécies de Eimeria presentes. Em $100 \%$ das fazendas avaliadas houve animais positivos para o protozoário. A frequência das espécies de Eimeria foi: $E$. ovinoidalis (94.74\%), E. crandallis (89.47\%), E. granulosa (78.95\%), E. parva (68.42\%), E. ahsata (63.13\%), E. punctata (42.11\%), E. bakuensis (36.84\%), E. faurei (10.53\%) e E. pallida (5.26). Infecção mista foi encontrada em $94.74 \%$ das amostras. Este trabalho descreve pela primeira vez a ocorrência de E. crandallis e E. ovinoidalis infectando cordeiros na área de estudo. Este trabalho descreve pela primeira vez a ocorrência de E. crandallis e E. ovinoidalis infectando cordeiros na área de estudo. A ampla distribuição desse protozoário e a alta frequência das espécies patogênicas evidenciam a importância da coccidiose ovina e os danos potenciais nos rebanhos do Rio Grande do Sul.

TERMOS DE INDEXAÇÃO: Infecção, cordeiros, Brasil, ovinocultura, coccidiose, Eimeria crandallis, Eimeria ovinoidalis, ovinos. 


\section{INTRODUCTION}

Traditionally, the sheep industry has always been relevant to the economy of the Rio Grande do Sul state. Even with the crises that occurred in the $80 \mathrm{~s}$ and $90 \mathrm{~s}$, the herd remains one of the largest in Brazil, and its distribution remains concentrated in the southern state region (Silva et al. 2013, IBGE 2017). This industry still faces some obstacles; parasitic infections being one of the factors that influences a reduction in sheep production performance. Among such diseases, coccidiosis causes significant economic losses as a result of clinical (diarrhea) and subclinical disease (poor weight gain) (Chartier \& Paraud 2012).

Coccidiosis of farm animals is caused by coccidial parasites of the genus Eimeria which develop in the small and the large intestines. Coccidiosis is of great economic importance, not only in terms of its effect on the animal (poor weight gain in particular) but also in terms of the required treatment costs. Many Eimeria infections in sheep are asymptomatic; however, more frequently in lambs, some species have been associated with diarrhea and stunted growth (Chartier \& Paraud 2012). Infections occur due to the ingestion of sporulated oocysts, and the hosts can be simultaneously infected by different species of the parasite. Currently, eleven Eimeria species are recognized as causing sheep infections, with $E$. crandallis and E. ovinoidalis being the most pathogenic (Andrews 2013). Species differentiation is still a challenge, requiring coprological examination with a precise morphometric analysis of sporulated oocysts (Macedo et al. 2019).

Clinical signs are unapparent in most Eimeria infected animals. However, it is common to have some degree of inappetence or anorexia, weight loss and growth retardation (Andrews 2013). Infection leads to underdevelopment due to parasite multiplication occurring within enterocytes, which causes villous atrophy, leading to malabsorption of nutrients (Martins et al. 2020). Fecal staining around the hindquarters, due to diarrhea, can occur. As the clinical conditions worsen, lambs develop profuse watery diarrhea that may contain blood-streaks (Keeton \& Navarre 2017). If treatment is not performed, intense dehydration can lead to death.

Subclinical disease and the non-specificity of clinical signs are obstacles to the detection of coccidiosis by farmers and veterinarians. Thus, the diagnosis must be based on the analysis of clinical signs, coprological examinations, animal management, age, and climatic factors (Martins et al. 2020).

Coccidiosis is a substantial problem, causing an important economic impact on livestock and, although the sheep industry is a traditional activity in Rio Grande do Sul, the epidemiology data of this parasitosis in the state are scarce, especially in the southern region.

Given that, the aim of this study was to estimate the frequency of Eimeria species in lambs from the southern Rio Grande do Sul state, Brazil.

\section{MATERIALS AND METHODS}

All procedures performed in this study were approved by the Ethics Commission on Animal Experimentation of the Federal University of Pelotas under protocol number 15450/2018.

A cross-sectional epidemiological study was carried out on 19 ruminant farms from 8 cities of the southern Rio Grande do Sul state, Brazil (Fig.1). The minimum sample size $(n=246)$ was estimated, with EpiInfoTM epidemiological calculators, based on the sheep population $(n=499,898)$ of the study area (IBGE 2019). A confidence level of $95 \%$ and statistical error of $5 \%$ were considered.

From August 2018 to September 2019, stool samples were collected directly from the rectum of 248 animals, which represented at least $10 \%$ of the total lambs from each farm. Analyzed farms adopted an intensive, extensive or semi-extensive production system. Animals enrolled in this study were observed for the presence of clinical signs related to coccidiosis (low body condition, diarrhea, apathy, and emaciation).

The samples were examined for the presence and number of oocysts per gram (OPG) of feces using the modified Gordon \& Whitlock technique (Ueno \& Gonçalves 1998). Subsequently, positive samples

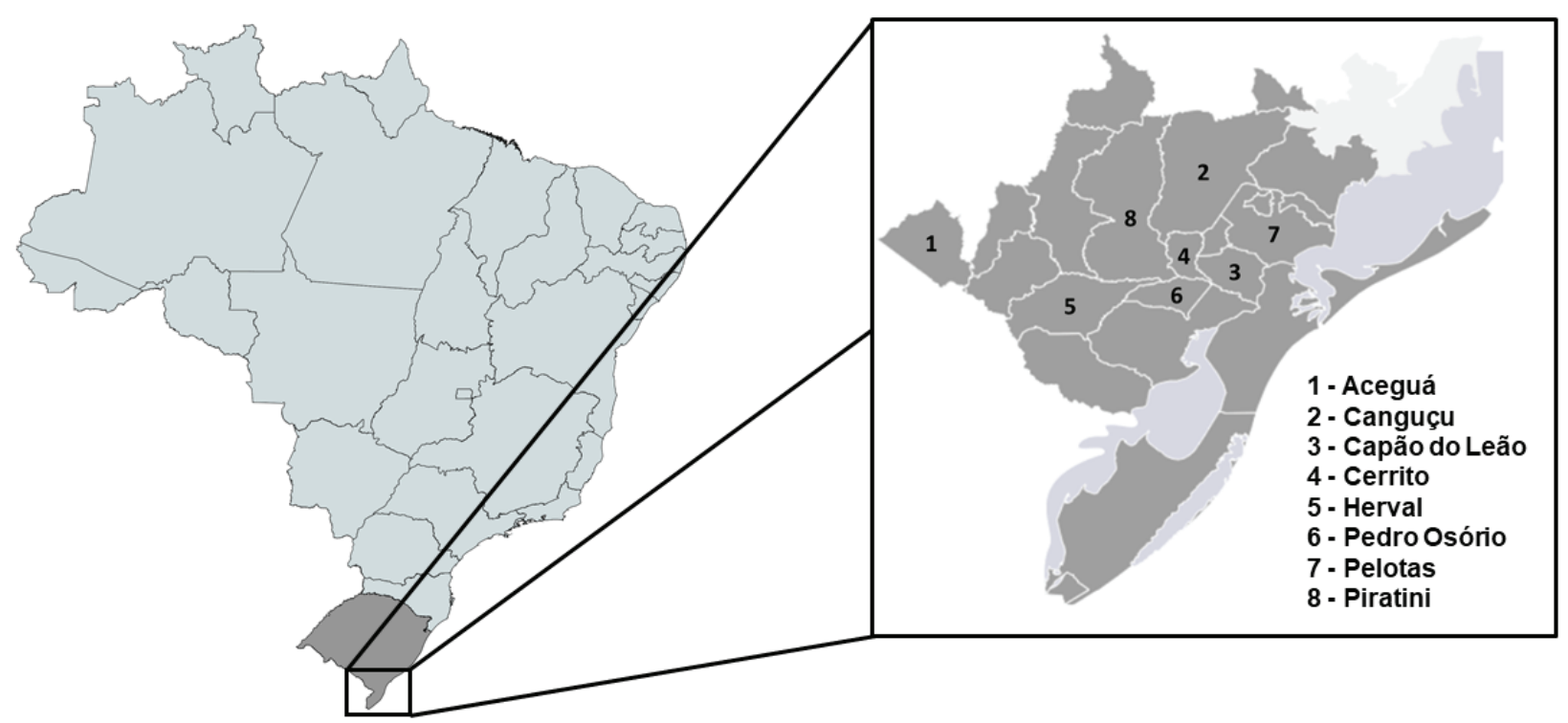

Fig.1. Municipalities from the southern Rio Grande do Sul state where lamb stool samples were collected for the detection of Eimeria in 2018 and 2019. 
from each farm were pooled and stored in Falcon tubes containing $2.5 \%$ potassium dichromate $\left(\mathrm{K}_{2} \mathrm{Cr}_{2} \mathrm{O}_{7}\right)$, which were regularly moved in order to allow oxygenation and kept at room temperature for ten days until sporulation of Eimeria oocysts was completed (Carrau et al. 2018). Sporulated oocysts were separated from the fecal mixture and potassium dichromate using a modified centrifugal flotation technique (Duszynski \& Wiiber 1997). Ultimately, 100 oocysts from each sample were randomly selected in the optical microscopy examination. In samples with less than 100 oocysts, all were analyzed. Species differentiation was based on morphometric and morphological characteristics, such as: shape, color, and presence or absence of micropyle and micropylar caps, following Souza et al. (2015) and Macedo et al. (2019).

For descriptive analysis, the Excel ${ }^{\circledR} 2019$ software package was used. True prevalence, and the Chi-square test, was performed to compare the occurrence of Eimeria species in different breeding systems, with a 5\% significance level, using EpiTools epidemiological calculators (Sergeant 2018).

\section{RESULTS}

Eimeria oocysts were found in $85.98 \%$ of the fecal samples with a mean of 5,034 oocysts per gram (OPG) of feces ( 0 a 120,100 OPG). Furthermore, at least one animal showed Eimeria infection in all farms (100\%). The overall results of positivity for any Eimeria species are shown in Table 1. Overall, 9 Eimeria species were identified in fecal samples with the following prevalence: E. ovinoidalis (94.74\%), E. crandallis (89.47\%), E. granulosa (78.95\%), E. parva (68.42\%), E. ahsata (63.13\%), E. punctata (42.11\%), E. bakuensis (36.84\%), E. faurei $(10.53 \%)$ and E. pallida (5.26\%). Concomitant infections were found in $94.75 \%$ of analyzed farms, with 3 to 8 different Eimeria species present in the same pooled sample (Table 1). No significant changes of color, odor or consistency were identified in the samples. Diarrhea was not observed in the analyzed lambs although, in some farms, poor body condition and apathy was noted.

\section{DISCUSSION}

The results obtained in this research showed that the Eimeria species has a wide distribution in the study area. Brazilian and worldwide studies have found a variable prevalence of Eimeria species in sheep; however, in the majority of cases,

Table 1. Presence of Eimeria oocysts in lambs from southern Rio Grande do Sul state, Brazil

\begin{tabular}{lccc}
\hline & Mean (OPG) & Median (OPG) & Frequency (\%) \\
\hline Farming systems & & & \\
$\quad$ Intensive & 5,971 & 1,000 & $95.24 \%^{\mathrm{a}}$ \\
Semi-extensive & 8,916 & 1,200 & $76 \%^{\mathrm{bc}}$ \\
Extensive & 4,250 & 1,100 & $87.8 \%^{\mathrm{ac}}$ \\
$P$ value & - & - & 0.0281 \\
Co-infections & & & \\
Triple & 7,805 & 3,600 & $10.54 \%^{\mathrm{a}}$ \\
Quadruple & 2,568 & 200 & $42.11 \%^{\mathrm{b}}$ \\
Quintuple & 4,561 & 1,100 & $31.58 \%^{\mathrm{ab}}$ \\
$>$ Six & 13,795 & 2,300 & $10.52 \%^{\mathrm{a}}$ \\
$P$ value & - & - & 0.0193 \\
OPG = Oocysts per gram; ${ }^{\mathrm{a}} \mathrm{b}, \mathrm{c}$ & Different lowercase letters on the same
\end{tabular}

column indicate a statistically significant difference (Chi-square $\mathrm{P}<0.05$ ). young animals had higher rates of positivity for the parasite (Lopes et al. 2013, Souza et al. 2015, Carrau et al. 2018). The high prevalence of positive samples found in the present study $(85.98 \%)$ probably occurred due to the focus on young lambs, the age group most susceptible to coccidiosis.

The pathogenic species for sheep, E. crandallis and $E$. ovinoidalis (Andrews 2013), were the most prevalent in the present study, which indicates that the evaluated farms have considerable risk for losses associated with coccidiosis. This is the first description of these species in the study area. The results are similar to the data found by Carrau et al. (2018), who obtained prevalence for E. ovinoidalis and E. crandallis of $97 \%$ and $89.4 \%$, respectively. These two species are usually associated with reduced fluid absorption and consequent diarrhea, but are also known to induce strong protective immunity without clinical signs (Carrau et al. 2018).

E. ahsata, E. bakuensis, E. granulosa, E. faurei, E. parva, E. pallida, and E. punctata are considered nonpathogenic but can cause impairment of growth due to nutrient malabsorption (Keeton \& Navarre 2017, Taylor et al. 2017), which might trigger subclinical coccidiosis in animals. Investigations carried out in different regions of Brazil already describe the presence of these species infecting sheep with variable prevalence (Tembue et al. 2009, Silva et al. 2011, Lopes et al. 2013, Souza et al. 2015, Macedo et al. 2019.

Previously studies demonstrated that the intensive and semi-intensive farming systems could facilitate the dissemination of Eimeria species (Lopes et al. 2013, Tomczuk et al. 2015). In this study, there were statistical differences $(\mathrm{p}=0.028)$ between animal infection and different breeding systems. Lambs raised under the intensive system had a higher frequency of parasitism by Eimeria (Table 1), with statistical difference in relation to the semi-extensive regime $(\mathrm{p}=0.010)$, which agrees with previous reports (Lopes et al. 2013, Macedo et al. 2019). In intensive breeding conditions accompanied by a high animal density, coccidiosis can become an infection of significant economic importance (Chartier \& Paraud 2012). Lower frequency was found in the semiextensive system, however the lambs raised in this regime has greater excretion of oocysts (Table 1). This fact could be related with the poor hygienic sanitary conditions and high stocking rates observed on some of these farms, which may be considered an aggravating factor for the spread of coccidiosis (Macedo et al 2019). Chartier \& Paraud (2012) suggested that the economic impact of coccidiosis in small ruminants from tropical regions is probably not of a significant impact compared with other infections; however, coccidiosis was considered a potential risk for sheep raised under extensive systems in Brazil (Silva et al 2011, Souza et al 2015). The high frequency of Eimeria infections and oocysts shedding found in extensive breeding, indicating that the presence of this parasite cannot be underestimated.

For Keeton \& Navarre (2017), mixed infections with multiple pathogenic and nonpathogenic species are common. This was observed in almost all positive lambs and suggests that these infections usually occur by more than one species in the study region. In fact, field-acquired infections are generally mixed, as the animals are more exposed to the existing environmental biodiversity (Silva et al. 2011).

Despite the high occurrence and the mixed infection of Eimeria species, no significant changes in stool characteristics, 
such as diarrhea, were observed. However, some animals presented at least one suggestive clinical sign of coccidiosis, such as poor body condition, rough hair coat, and apathy. A poor growth rate, in an appropriate epidemiological setting, should indicate a diagnosis of subclinical coccidiosis (Chartier \& Paraud 2012), with consequent economic losses for farmers. The non-specificity or nonexistence of clinical signs makes coprological monitoring essential to identify losses in livestock production, as is the development of partnerships between veterinarians and farmers.

So far, little is known about ovine coccidiosis in the southern Rio Grande do Sul region. This study on natural infections of Eimeria species is considered to contribute to the better understanding of coccidiosis epidemiology in this study area. New studies should be encouraged to elucidate the risk factors of these parasites, emphasizing the need to develop diagnostic and control programs, contributing to the progress of the sheep industry.

\section{CONCLUSIONS}

The results obtained in this research showed that Eimeria species constitute an endemic infection on the evaluated farms, with a wide distribution of the parasite. Eimeria ovinoidalis and Eimeria crandallis was the most frequent species, followed by Eimeria granulosa, Eimeria parva, Eimeria ahsata, Eimeria punctata, Eimeria bakuensis, Eimeria faurei, and Eimeria pallida.

Higher levels of parasitism were diagnosed in animals that were raised in an intensive breeding system $(\mathrm{P} \leq 0.05)$.

Concomitant infections were found in almost all analyzed farms.

The high frequency of this protozoan, and the description of the pathogenic species E. crandallis and E. ovinoidalis for the first time in the region, highlight the importance of sheep coccidiosis in the southern Rio Grande do Sul state, Brazil.

Acknowledgments.- This study was financed in part by the "Coordenação de Aperfeiçoamento de Pessoal de Nível Superior" (CAPES), Brazil, Finance Code 001. The authors would also like to express their gratitude and appreciation to the farmers and veterinarians who participated in this research.

Conflict of interest statement.- The authors have no competing interests.

\section{REFERENCES}

Andrews A.H. 2013. Some aspects of coccidiosis in sheep and goats. Small Rumin. Res. 110(2/3):93-95. <https://dx.doi.org/10.1016/j. smallrumres.2012.11.011>

Carrau T., Silva L.M.R., Pérez D., Failingd K., Martínez-Carrasco C., Macías J., Taubert A., Hermosilla C. \& Ruiz de Ybáñez R. 2018. Associated risk factors influencing ovine Eimeria infections in southern Spain. Vet. Parasitol. 263:54-58. <https://dx.doi.org/10.1016/j.vetpar.2018.10.004>

Chartier C. \& Paraud C. 2012. Coccidiosis due to Eimeria in sheep and goats, a review. Small Rumin. Res. 103(1):84-92. <https://dx.doi.org/10.1016/j. smallrumres.2011.10.022>
Duszynski D.W. \& Wiiber P.G. 1997. A guideline for the preparation of species descriptions in the Eimeriidae. J. Parasitol. 83(2):333-336.<PMid:9105325>

IBGE 2017. Produção da Pecuária Municipal 2017. Prod. Pec. Mun., Rio de Janeiro, 45:1-8.

IBGE 2019. Censo Agropecuário 2017. Censo Agropec., Rio de Janeiro, 8:1-105.

Keeton S.T.N. \& Navarre C.B. 2017. Coccidiosis in Large and Small Ruminants. Vet. Clin. N. Am., Food Anim. Pract., 34(1):201-208. <https://dx.doi. org/10.1016/j.cvfa.2017.10.009><PMid:29249601>

Lopes W.D.Z., Borges F.A., Faiolla T.P., Antunes L.T., Borges D.G.L., Rodriguez F.S., Ferraro G., Teixeira W.F., Maciel W.G., Felippelli G., Costa A.J., Pereira V. \& Martinez A.C. 2013. Eimeria species in young and adult sheep raised under intensive and/or semi-intensive systems of a herd from Umuarama city, Parana State, Brazil. Ciência Rural 43(11):2031-2036. <https://dx.doi. org/10.1590/S0103-84782013001100018>

Macedo L.O., Santos M.A.B., Silva N.M.M., Barros G.M.M.R., Alves L.C., Giannelli A., Ramos R.A.N. \& Carvalho G.A. 2019. Morphological and epidemiological data on Eimeria species infecting small ruminants in Brazil. Small Rumin. Res. 171:37-41.<https://dx.doi.org/10.1016/j.smallrumres.2018.12.006>

Martins N.S., Motta S.P., Santos C.C., Moreira A.S., Farias N.A.R. \& Ruas J.L. 2020. Eimeriose em bovinos e ovinos: uma inimiga invisível. Braz. J. Develop. 6(4):19421-19434.<https://dx.doi.org/10.34117/bjdv6n4-201>

Sergeant E.S.G. 2018. Epitools Epidemiological Calculators. Ausvet. Available at <http://epitools.ausvet.com.au> Accessed on Apr. 15, 2020.

Silva A.P.S.P., Santos D.V., Kohek Jr I., Machado G., Hein H.E., Vidor A.C.M. \& Corbellini L.G. 2013. Ovinocultura do Rio Grande do Sul: descrição do sistema produtivo e dos principais aspectos sanitários e reprodutivos. Pesq. Vet. Bras. 33(12):1441-1446. <https://dx.doi.org/10.1590/S0100736X2013001200010>

Silva R.M., Facury-Filho E.J., Souza M.F. \& Ribeiro M.F.B. 2011. Natural infection by Eimeria spp. in a cohort of lambs raised extensively in Northeast Brazil. Braz. J. Vet. Parasitol. 20(2):134-139. <https://dx.doi.org/10.1590/S198429612011000200008>

Souza L.E.B., Cruz J.F., Teixeira Neto M., Albuquerque G.R., Melo A.D.B. \& Tapia D.M.T. 2015. Epidemiology of Eimeria infections in sheep raised extensively in a semiarid region of Brazil. Revta Bras. Parasitol. Vet. 24(4):410-415. <https://dx.doi.org/10.1590/S1984-29612015070><PMid:26648007>

Taylor M.A., Coop R.L. \& Wall R.L. 2017. Parasitologia Veterinária. 4aㅡ ed. Guanabara Koogan, Rio de Janeiro, p.1733-1758.

Tembue A.A.S.M., Ramos R.A.N., Lima M.M., Faustino M.A.G., Meunier I.M.J. \& Alves L.C. 2009. Species of the genus Eimeria Schneider, 1875 (Apicomplexa: Eimeriidae) in small ruminants from Ibimirim county, Pernambuco state. Vet. Not. 15(2):51-57.

Tomczuk K., Grzybek M., Szczepaniak K., Studzinska M., Demkowska-Kutrzepa M., Roczen-Karczmarz M. \& Klockiewicz M. 2015. Analysis of intrinsic and extrinsic factors influencing the dynamics of bovine Eimeria spp. from central-eastern Poland. Vet. Parasitol. 214(1/2):22-28. <https://dx.doi. org/10.1016/j.vetpar.2015.09.027><PMid:26455571>

Ueno H. \& Gonçalves P.C. 1998. Manual para Diagnóstico das Helmintoses de Ruminantes. 4aㅡ ed. JICA, Tokyo, p.16-18. 